\title{
Los tipos de iniciativas empresariales de los inmigrantes en las ciudades de Barcelona, Madrid y Valencia
}

\author{
Leonardo Cavalcanti \\ Universidad Autónoma de Barcelona \\ leonardo.cavalcanti@uab.es
}

\begin{abstract}
Resumen
El principal objetivo de este artículo es presentar una tipología, de carácter cualitativo, de los perfiles de los empresarios de origen inmigrante procedentes de paises no comunitarios en España, y de las características de sus negocios. Se trata de ilustrar, en términos de representatividad tipológica, los rasgos y el potencial de las empresas regentadas por inmigrantes. Dicho análisis se realiza a partir del estudio titulado «El empresariado inmigrante en España» (Solé, Parella y Cavalcanti, 2007), financiado por la Fundación La Caixa, en tres contextos socioespaciales concretos donde se da una elevada concentración de población extranjera: Barcelona, Madrid y Valencia.
\end{abstract}

Palabras clave: iniciativas empresariales de los inmigrantes, España, tipología

\begin{abstract}
The principal aim of this article is to present a qualitative typology of the profiles of immigrant entrepreneurs from non-European Union countries living in Spain, as well as the characteristics of their businesses. The intention is to illustrate typologically the characteristics and the potential of businesses run by immigrants. This analysis is based on a study called «El empresariado inmigrante en España» (Immigrant Businesses in Spain) (Solé, Parella $y$ Cavalcanti, 2007), financed by the La Caixa Foundation. It looks at three specific sociospatial contexts where there is a bigher concentration of foreign people: Barcelona, Madrid and Valencia.
\end{abstract}

Key words: immigrant business initiatives, Spain, typology 


\section{Introducción}

El presente texto se centra en el análisis de los tipos de empresas regentadas por inmigrantes en las ciudades de Barcelona, Madrid y Valencia. A lo largo de los distintos apartados se examina la tipología de las iniciativas empresariales de los inmigrantes radicados en España en relación con el tipo de actividad desarrollada, la ubicación en el espacio urbano y la clientela.

En otros países marcados por el fenómeno de la inmigración, diferentes investigadores han elaborado tipologías para clasificar las empresas regentadas por inmigrantes. Una clasificación extensa la proporciona Ambrosini (1996), que analiza cinco tipos de empresas. En primer lugar, las empresas típicamente étnicas, que ofertan productos y servicios dirigidos a satisfacer las demandas de la comunidad inmigrada (carnicerías y productos alimenticios). En segundo lugar, las empresas intermediarias, que dispensan productos no típicamente étnicos, sino destinados a los consumidores connacionales; en este caso, suele tratarse de servicios, abogados, médicos, agencias de crédito, etc. En tercer lugar, las empresas exóticas, que ofrecen productos específicos del lugar de origen de los inmigrados a un público heterogéneo, como determinados espectáculos, restaurantes, etc. En cuarto lugar, las empresas abiertas, que apenas se identifican con el grupo étnico y se orientan a las finanzas y servicios en general. Por último, las empresas refugio, difíciles de catalogar por la variedad de productos y servicios que ofertan, caracterizadas por su situación de marginalidad (comercio ambulante, cortar el pelo o adornar el cuerpo en domicilios, etc.).

Otros autores distinguen las iniciativas empresariales de los inmigrantes que dirigen sus productos y servicios a sus coétnicos (orientación interna o étnica) de los que se orientan al mercado general (orientación externa o no étnica). Éste es el caso de Jones, Barrett y McEvoy (2000) en su estudio comparativo sobre las iniciativas empresariales de los inmigrantes en el Reino Unido y Canadá.

A partir de los datos cualitativos recogidos en el estudio titulado «El empresariado inmigrante en España», dirigido por la Dra. Carlota Solé y financiado por la Fundación La Caixa (Solé, Parella y Cavalcanti, 2007), se analizan los diferentes tipos de empresas regentadas por los inmigrantes en las ciudades de Barcelona, Madrid y Valencia. En términos generales, se puede afirmar que las actividades empresariales desarrolladas por los inmigrantes se caracterizan por su pluralidad. Estas actividades emprendedoras se pueden agrupar en torno a las siguientes áreas: espacios asociativos (de solidaridad, de deportes, de cooperación internacional, de culto, ONG, etc.); establecimientos comerciales (alimentación, panaderías, peluquerías, restaurantes, bares, discotecas, empresas de informática, locutorios, artesanías, tiendas import-export, inmobiliarias, tiendas y talleres de coches, etc.); profesiones liberales (centros de salud, 
asesoría jurídica, enseñanza, terapias alternativas, diseño y publicidad, informática, artísticas, fiesta y animación, organización de eventos, etc.) y medios de comunicación (radios, periódicos, revistas, imprenta, productoras, etc.).

A partir de la diversidad de iniciativas empresariales anteriormente descritas, en las siguientes páginas se presenta una tipología de empresas regentadas por inmigrantes, independientemente de su participación o no en la esfera mercantil.

\section{Los tipos de empresas regentadas por inmigrantes}

Los estudios desarrollados en el seno de países con una larga presencia de población inmigrante constatan que la clave del éxito empresarial de las minorías étnicas pasa por cierta autosegregación de este colectivo, lo que proporciona redes y espacios de intercambio comercial en zonas donde se da una mayor densidad de estas comunidades (Bonacich y Modell, 1980; Light, 1979). Sin embargo, en muchos de los negocios estudiados en Barcelona, Madrid y Valencia, sus propietarios también adoptan estrategias sectoriales, creando sus iniciativas empresariales en espacios urbanos que no se caracterizan por una elevada concentración de inmigrantes.

Las investigaciones desarrolladas en las principales ciudades de España coinciden en señalar que la apertura de empresas de inmigrantes, en ciudades como Barcelona, Madrid y Valencia, tiene lugar en un contexto de larga crisis del pequeño comercio tradicional de base familiar, revitalizado por la reciente presencia de los inmigrantes (Aramburu, 2002; Solé y Parella, 2005; Cebrián y Bodega, 2002). De este modo, las empresas de los emigrantes contribuyen a impulsar la economía de barrios anteriormente degradados.

Así, las zonas de Barcelona, Madrid y Valencia, donde hay mayor número de iniciativas empresariales de inmigrantes, son espacios que estaban comercialmente deprimidos en décadas anteriores. La presencia de empresas administradas por personas de origen extranjero en estas zonas dinamiza las actividades comerciales, económicas y sociales, antes caracterizadas por un alto grado de degradación. En este sentido, Solé y Rodríguez (2004: 111-112) afirman que los comercios regentados por inmigrantes tienen un efecto dinamizador sobre la economía del barrio, especialmente en las dos últimas décadas, cuando la tendencia del comercio autóctono en el barrio ha sido cerrar sus puertas como resultado de la «crisis del pequeño comercio». Esta crisis se fundamenta, según los propios comerciantes, en la competencia de las grandes superficies, la disminución de la población con mayor poder adquisitivo, el incremento constante de impuestos y la falta de relevo generacional, entre otros aspectos. 
En esa misma línea, Sassen (1997) observa que el empresariado inmigrante promueve el desarrollo económico de zonas degradadas de la ciudad, lo que genera una nueva dinámica comercial y da lugar a un proceso revitalizador de estos espacios a través de mercados alternativos con una demanda y una oferta propias.

Con todo, hay que considerar el riesgo de saturación que se deriva del hecho de que muchos negocios se concentren en determinados barrios y zonas de la ciudad. Por esta razón, algunos inmigrantes reconocen la necesidad de orientarse hacia un mercado más abierto y expansivo, hacia una clientela más diversificada.

Los casos estudiados apuntan, precisamente, al riesgo de saturación como razón para diversificar el negocio, tanto desde el punto de vista geográfico, en las diferentes zonas de la ciudad, como en lo concerniente a los productos y al modo de funcionamiento. Además, la falta de concentración espacial de personas de un mismo origen étnico hace necesaria la diversificación y dinamización por parte de los inmigrantes emprendedores.

De este modo, los inmigrantes están apostando cada vez más por empresas que se caracterizan por su diferenciación y diversidad en muchos sentidos. El protagonismo empresarial/emprendedor de los emigrantes es una característica pujante en distintas zonas del escenario urbano barcelonés, madrileño y valenciano. La actividad comercial de los emigrantes aporta nuevo dinamismo económico en dichas ciudades. Sin lugar a dudas, es un elemento del paisaje urbano español.

A continuación, se analizan de forma sucinta cinco tipos de empresas: empresas de orientación étnica, empresas circuito, empresas especializadas en población inmigrante, empresas que explotan lo exótico y empresas generalistas.

\subsection{Empresas de orientación étnica}

Las empresas de orientación étnica se caracterizan por su papel como promotoras de productos, símbolos y servicios destinados a las demandas de las comunidades nacionales y/o étnicas inmigradas en España. Este tipo de empresas abarca desde las iniciativas empresariales dedicadas a comercializar y difundir símbolos culturales a través de periódicos, ONG, actividades culturales, programas de radio y televisión o revistas hasta las que producen o distribuyen bebidas y comestibles propios de los países de origen.

En los últimos años ha aumentado el número de empresas que se dedican a difundir símbolos culturales relativos a los países de origen de los emigrantes. Así, se constata un incremento significativo de periódicos y revistas destinadas a ofrecerles información. Dichas iniciativas tienen como propósito divulgar, en España, la cultura 
de los países de origen, así como información de la vida cotidiana en las ciudades de destino.

En el conjunto de las empresas de orientación étnica que explotan los medios de comunicación, la mayoría de los trabajadores son periodistas de origen inmigrante, aunque también hay muchos autóctonos propietarios de este tipo de medio informativo. Son españoles, vinculados al mundo del periodismo, que explotan la oportunidad de mercado que significa la conversión de España en un país de inmigración.

Por otra parte, están las empresas de orientación étnica que se dedican a distribuir o producir bebidas y comestibles típicos de las sociedades de origen de los emigrantes (carnicerías halal, panaderías o restaurantes, entre otros); también se incluyen aquí algunas peluquerías. Se trata, pues, de una gama de negocios que pretenden satisfacer una demanda específica. Son actividades comerciales que cuentan con un público fundamentalmente de origen inmigrante. No obstante, también cuentan con clientela autóctona, ya sea por la calidad del producto, los gustos o las tendencias, ya sea por sus precios más competitivos.

Este tipo de comercios, sobre todo los dedicados a la restauración y las peluquerías, más allá del servicio o producto que dispensan, se convierten en lugares de reunión y espacios donde se construyen relaciones entre los inmigrantes. En definitiva, constituyen un espacio donde pueden encontrar soluciones a las necesidades básicas de su vida cotidiana en España, como encontrar un alojamiento provisional o un puesto de trabajo.

Por otro lado, las empresas de orientación étnica se localizan en los barrios donde se da una mayor concentración de inmigrantes. En su mayoría, los trabajadores de estas empresas son también inmigrantes, pero ofrecen sus servicios a una clientela más amplia, que incluye tanto a las distintas nacionalidades extranjeras como a los autóctonos.

\subsection{Empresas circuito}

Las empresas circuito son el arquetipo de la empresa comercial transnacional. La necesidad que tienen los emigrantes de mantener un contacto regular con sus connacionales en el país de origen ofrece el terreno propicio para el desarrollo de estas actividades comerciales.

Las actividades transnacionales son heterogéneas y varían entre las distintas comunidades emigrantes, tanto en intensidad como en contenido. Así, varían en función de las estructuras familiares y de amistad, de las condiciones materiales de existencia de los emigrantes en el país de origen y en el receptor, de las rutas de transporte disponi- 
bles, del tipo y el grado de acceso a las tecnologías de la comunicación, de las facilidades para la circulación de remesas y de las estructuras financieras, de los marcos legislativos que afectan a los movimientos de personas, así como de los vínculos económicos de las economías locales (Portes et alii, 2003; Vertovec, 2004). Ahora bien, es necesario destacar, de acuerdo con Faist (2000), que no todos los emigrantes desarrollan prácticas transnacionales y que muchos lo hacen sólo en una esfera determinada de sus vidas.

Sin lugar a dudas, las tecnologías, por sí mismas, no crean nuevos espacios sociales transnacionales, pero contribuyen a reforzar y transformar los preexistentes (Castells, 1997). Con el desarrollo de las nuevas tecnologías en torno al transporte y la comunicación se intensifican y densifican las conexiones transnacionales (Vertovec, 2001, 2004). Las nuevas tecnologías, entre otros factores, contribuyen a la formación de una red de transacciones globalizadas de datos, bienes, servicios y recursos humanos. Como resultado de estos procesos, el centro de gravedad de la acción social supera las sociedades o los sistemas sociales tal y como estamos acostumbrados a concebirlos.

Actualmente, en un contexto de globalización, las migraciones son transnacionales, por cuanto trascienden las fronteras geográficas y económicas entre las diferentes zonas del planeta e implican a varios países en red, que constituyen unidades de organización productiva y redistributiva, a escala planetaria y en tiempo real (Castells, 1997). A través de los espacios transnacionales, «los migrantes construyen una tupida red de relaciones e intercambios que incluyen inversiones, transferencias tecnológicas, iniciativas empresariales, innovaciones y transacciones comerciales» (Abad, 2005: 125).

Así, en la actualidad, son muchos los emigrantes que crean empresas dedicadas a potenciar estas nuevas formas de materialización de la interacción transnacional que establecen los inmigrantes entre las dos sociedades involucradas en el proceso migratorio: la sociedad de emigración y la de inmigración. Las empresas circuito abarcan todo tipo de actividad que facilite esa interacción transnacional entre países de origen y de destino. Buen ejemplo de ello son los locutorios, las agencias de envío de dinero y las tiendas import-export, entre otras.

Estas empresas suelen instalarse en zonas con una alta densidad de población inmigrante. La mayoría de sus trabajadores son inmigrantes y la clientela está formada principalmente por extranjeros. En algunos locutorios, sin embargo, hay un elevado número de clientes autóctonos, tanto de los servicios de teléfono como de Internet. Esto se debe al hecho de que algunos inmigrantes diversifican el tipo de servicio para crear vínculos y atraer a más clientes. 


\subsection{Empresas especializadas en población inmigrante}

El tercer tipo de negocio, correspondiente a las empresas especializadas en población inmigrante, engloba un conjunto de profesionales liberales, inmobiliarias, asesoría jurídica y ONG, entre otros. Se trata de empresas que, en su mayoría, se dedican exclusivamente al público inmigrante, ya sea por la carencia de los permisos de residencia y de trabajo, por las dificultades lingüísticas, por la apertura de nuevos mercados, etc.

Son empresas que se concentran en las zonas donde se da mayor densidad residencial de inmigrantes, de modo que, en general, tanto los propietarios como los trabajadores son inmigrantes. Por otra parte, la estructura de funcionamiento y la atención al cliente suelen ser muy similares a las de las empresas presentes en el país de origen.

En términos generales, los inmigrantes que regentan empresas especializadas en población inmigrante consideran la necesidad de diversificar el servicio para compensar el riesgo de saturación que hay implícito en este tipo de actividad. Son las iniciativas empresariales más vulnerables a la competencia, puesto que dependen exclusivamente de la clientela inmigrante. En este sentido, muchos emigrantes emprendedores aluden a la necesidad de diversificar los productos con la finalidad de ampliar la clientela a los diferentes colectivos de inmigrantes residentes en España.

\subsection{Empresas que explotan lo exótico}

El cuarto tipo de empresa está representado por los negocios que explotan lo exótico. Entre los prototipos más comunes de empresas que se caracterizan por utilizar lo étnico, en tanto que exótico para un público amplio, se encuentran algunos restaurantes, tiendas de artesanía, terapias alternativas, empresas fiesta y animación, entre otras.

También está el caso de algunos comerciantes que comercializan productos típicos y artesanía de sus países, fabricados tanto en el país de origen como en otros países, por ejemplo en China. Éste es el caso de algunos comercios que venden muchos de sus productos como oriundos y manufacturados en el país de origen, aunque muchos de ellos se fabrican en otras regiones.

Por otro lado, este tipo de empresas están regentadas no sólo por población inmigrante, sino también por autóctonos que mantienen algún tipo de vínculo con un determinado país.

La explotación de lo exótico, o el proceso de exotización, se puede entender asimismo, según Machado (2003), como la exacerbación, consolidación y esencialización de estereotipos de los países de origen de los inmigrantes. Estos procesos se perciben claramente en el modo como algunos inmigrantes apuestan por una determinada acti- 
vidad comercial. Así, algunos negocios dan una imagen «exotizada» de sus respectivos países de origen.

La utilización exagerada de lo étnico como exótico esconde una posición simbólicamente subordinada, en el contexto de la sociedad de inmigración. En otras palabras, crea procesos de esencialización que sitúan al inmigrante perteneciente a ese origen nacional en una especie de «cárcel pública» (Machado, 2003: 18).

\subsection{Empresas generalistas}

La quinta y última forma de empresas regentadas por inmigrantes corresponde a las empresas generalistas, categoría que abarca bares, establecimientos de electrodomésticos y de informática, supermercados, empresas de construcción y reparación, y consultorías, entre otras. En España, las nuevas actividades comerciales de los inmigrantes buscan desmarcarse progresivamente de un modelo asociado a lo étnico o a lo transnacional, para intentar acceder a una parcela mayor del mercado, que incluya a autóctonos, inmigrantes y extranjeros en general.

Se trata de iniciativas empresariales que no tienen interés en ofrecer un producto asociado a los países de origen de los emigrantes. En este sentido, son empresas que no se diferencian, en lo más mínimo, del modo de funcionamiento o de la estructura de las empresas autóctonas; e intentan que su clientela sea la más diversa posible. Además, la mano de obra de estas empresas no necesariamente está formada por inmigrantes.

Las empresas generalistas están creciendo de modo considerable en España. Así, es cada vez mayor el número de inmigrantes que adoptan estrategias comerciales que puedan satisfacer las necesidades de un público más amplio. Uno de los factores que explican el aumento de este tipo de empresas son las posibles dificultades que se seguirían de una situación objetiva de saturación o disminución de las oportunidades de una actividad comercial destinada exclusivamente a la población inmigrante o connacional.

Según Waldinger, McEvoy y Aldrich (1990), el riesgo de saturación de los negocios destinados a atender a un público formado exclusivamente por inmigrantes es elevado, a medio y largo plazo. Es necesario saber encaminarse hacia un mercado más abierto, como demuestra la trayectoria seguida por muchos de estos negocios en países tradicionalmente receptores de mano de obra inmigrante. Al igual que en Estados Unidos y en las ciudades europeas con mayor presencia de inmigrantes, en España se da una tendencia a buscar actividades que se desmarcan tanto de lo étnico como de lo transnacional. En este sentido, son muchos los negocios que anteriormente estaban dedicados a una población exclusivamente inmigrante y que, en la actualidad, se han 
reestructurado y han convertido sus productos o servicios en atractivos para el conjunto de la población.

En los barrios con mayor concentración de negocios regentados por inmigrantes, como es el caso de Lavapiés, el Raval y Russafa, en Madrid, Barcelona y Valencia, respectivamente, muchos negocios que en un principio tenían una orientación exclusivamente étnica, se dirigen actualmente a una población más general. Se trata de empresas que abarcan ramas de actividad cada vez más diversificadas: establecimientos comerciales, talleres, asociaciones, empresas culturales, entre otras.

\section{Conclusiones}

En la tabla 1 se presentan de forma sintética los cinco tipos de empresas presentadas en las páginas precedentes.

Muchos de los negocios clasificados con rasgos específicos de un determinado tipo de empresa (por ejemplo, negocios de orientación étnica) pueden combinar características de otro perfil de iniciativas empresariales, como las empresas circuito.

La mayoría de las tipologías presentadas en diferentes estudios migratorios (Ambrosini, 1996; Waldinger, 1989; Jones, Barrett y McEvoy, 2000) se articulan a lo largo de uno o varios ejes analíticos. La tipología ofrecida en estas páginas sigue esa misma lógica y constituye fundamentalmente un trabajo clasificatorio de las diferentes empresas regentadas por inmigrantes.

Por otro lado, entre los diferentes tipos de empresas regentadas por inmigrantes, se observa una importante proliferación de negocios orientados a satisfacer las «nuevas» demandas del conjunto de la población inmigrante en general, a nivel de barrio. Ejemplo de ello son las tiendas de alquiler de películas de los respectivos países de origen, supermercados especializados en alimentos étnicos, empresas destinadas a promover el deporte entre los inmigrantes, bares con karaokes, entre otras.

Según la clientela a la que se orientan los negocios, se puede distinguir un amplio número de establecimientos, desde los que ofrecen productos específicos para inmigrantes hasta aquellos que proporcionan artículos y servicios dirigidos a un público más general. Son estos últimos los que predominan en las ciudades de Barcelona, Madrid y Valencia. Al diferenciar las empresas de inmigrantes en cuanto al tipo de clientela, destaca la pluralidad. Incluso en aquellos negocios más especializados, como las carnicerías halal o las peluquerías africanas, hay una habitual presencia de clientela autóctona. 
Tabla 1. Tipología de las empresas regentadas por los inmigrantes en España

\begin{tabular}{|c|c|c|c|c|}
\hline Tipo de empresa & $\begin{array}{l}\text { Zona de } \\
\text { ubicación }\end{array}$ & $\begin{array}{l}\text { Mano de } \\
\text { obra }\end{array}$ & $\begin{array}{l}\text { Perfil nacional/ } \\
\text { transnacional }\end{array}$ & $\begin{array}{l}\text { Público/ } \\
\text { consumo }\end{array}$ \\
\hline $\begin{array}{l}\text { Empresas de } \\
\text { orientación étnica } \\
\text { (prensa, panaderías, } \\
\text { carnicerías balal...) }\end{array}$ & $\begin{array}{l}\text { Área de } \\
\text { concentración } \\
\text { residencial de } \\
\text { inmigrantes. }\end{array}$ & $\begin{array}{l}\text { Inmigrantes en } \\
\text { su mayoría. }\end{array}$ & $\begin{array}{l}\text { Promueve } \\
\text { los vínculos } \\
\text { transnacionales. }\end{array}$ & $\begin{array}{l}\text { Inmigrantes en } \\
\text { su mayoría. }\end{array}$ \\
\hline $\begin{array}{l}\text { Empresas circuito } \\
\text { (locutorios, } \\
\text { mensajería, envío de } \\
\text { dinero...) }\end{array}$ & $\begin{array}{l}\text { Área de } \\
\text { concentración } \\
\text { residencial de } \\
\text { inmigrantes. }\end{array}$ & $\begin{array}{l}\text { Inmigrantes en } \\
\text { su mayoría. }\end{array}$ & $\begin{array}{l}\text { Promueve } \\
\text { los vínculos } \\
\text { transnacionales. }\end{array}$ & $\begin{array}{l}\text { Inmigrantes en } \\
\text { su mayoría. }\end{array}$ \\
\hline $\begin{array}{l}\text { Empresas } \\
\text { especializadas en } \\
\text { población inmigrante: } \\
\text { ofrecen servicios } \\
\text { o productos para } \\
\text { los connacionales } \\
\text { o emigrantes en } \\
\text { general (inmobiliarias, } \\
\text { asesoría jurídica, } \\
\text { profesionales liberales, } \\
\text { ONG) }\end{array}$ & $\begin{array}{l}\text { Área de } \\
\text { concentración } \\
\text { residencial de } \\
\text { inmigrantes. }\end{array}$ & $\begin{array}{l}\text { Autóctonos, } \\
\text { inmigrantes y } \\
\text { extranjeros en } \\
\text { general. }\end{array}$ & $\begin{array}{l}\text { Centrada en el país } \\
\text { de inmigración. }\end{array}$ & $\begin{array}{l}\text { Inmigrantes, } \\
\text { autóctonos y } \\
\text { extranjeros en } \\
\text { general. }\end{array}$ \\
\hline $\begin{array}{l}\text { Empresas que explotan } \\
\text { lo exótico: utilizan lo } \\
\text { étnico como exótico } \\
\text { para un público } \\
\text { amplio (restaurantes, } \\
\text { tiendas de artesanía, } \\
\text { terapias alternativas, } \\
\text { fiesta y animación...) }\end{array}$ & $\begin{array}{l}\text { Agrupación } \\
\text { sectorial de } \\
\text { acuerdo con las } \\
\text { características } \\
\text { del producto. }\end{array}$ & $\begin{array}{l}\text { Autóctonos, } \\
\text { inmigrantes y } \\
\text { extranjeros en } \\
\text { general. }\end{array}$ & $\begin{array}{l}\text { Centrada en el país } \\
\text { de inmigración. }\end{array}$ & $\begin{array}{l}\text { Inmigrantes, } \\
\text { autóctonos y } \\
\text { extranjeros en } \\
\text { general. }\end{array}$ \\
\hline $\begin{array}{l}\text { Empresas } \\
\text { generalistas (bares, } \\
\text { establecimientos de } \\
\text { electrodomésticos y de } \\
\text { informática, empresas } \\
\text { de construcción, } \\
\text { informática, } \\
\text { supermercados...) }\end{array}$ & $\begin{array}{l}\text { Agrupación } \\
\text { sectorial de } \\
\text { acuerdo con las } \\
\text { características } \\
\text { del producto. }\end{array}$ & $\begin{array}{l}\text { Autóctonos, } \\
\text { inmigrantes y } \\
\text { extranjeros en } \\
\text { general. }\end{array}$ & $\begin{array}{l}\text { Centrada en el país } \\
\text { de inmigración. }\end{array}$ & $\begin{array}{l}\text { Inmigrantes, } \\
\text { autóctonos y } \\
\text { extranjeros en } \\
\text { general. }\end{array}$ \\
\hline
\end{tabular}

Fuente: Solé, Parella y Cavalcanti (2007).

De igual modo, diferenciar las empresas de inmigrantes en España del resto a partir de las condiciones laborales de los trabajadores asalariados resulta arriesgado. Según Aramburu (2002), hasta cierto punto, en el comercio autóctono de base familiar, hay personas de confianza que normalmente trabajan sin contrato laboral, con pagas más bajas y jornadas más largas que las habituales en el mercado de trabajo general. 
En definitiva, los diferentes tipos de iniciativas empresariales de los inmigrantes introducen un prisma nuevo en los estudios sobre las migraciones, en tanto que obligan a superar los enfoques que han abordado la inmigración casi exclusivamente como fuerza de trabajo por cuenta ajena.

\section{Bibliografía}

Aваd, L. (2005). «Impacto de la migración y las remesas en el desarrollo», Migraciones, $18: 105-148$.

Ambrosini, M. (1996). "Ethnicité et marché du travail: les immigrés dans le système économique italien», Sociologia del Lavoro, 66-67: 307-327.

Aramburu, M. (2002). «Los comercios de inmigrantes extranjeros en Barcelona y la recomposición del 'inmigrante' como categoría social», Scripta Nova. Revista electrónica de geografia y ciencias sociales, VI (108). <http://www.ub.es/geocrit/sn/sn-108. htm $>$.

Boissevain, J. et alii (1990). «Ethnic entrepreneurs and ethnic strategies», en Waldinger, R. et alii (eds.). Ethnic Entrepreneurs. Immigrant Business in Industrial societies. Londres: Sage.

Bonacich, E.; Modell, J. (1980). The economic basis of ethnic solidarity in the Japanese American Community. Berkeley: University of California Press.

Castells, M. (1997). La era de la información, vol. 1: La sociedad-red. Madrid: Alianza Editorial.

Cebrián, J. A.; Bodega, M. ${ }^{a}$ I. (2002). «El negocio étnico, nueva fórmula de comercio en el casco antiguo de Madrid. El caso de Lavapiés», Estudios Geográficos, LXIII (248/249): 559-580.

FAIst, Th. (2000). The Volume and Dynamics of International Migration and Transnational Social Spaces. Oxford: Oxford University Press.

Jones, T.; Barrett, G.; McEvoy, D. (2000). «Market Potential as a Decisive Influence on Performance of Ethnic Minority Business», en: Rath, J. (ed.). Inmigrant Business. The economic, politic and Social Environment, Warwick: University of Warwick / Center for Research in Ethnic Relations.

Machado, I. (2003). Cárceres público: processos de exortização entre imigrantes brasileiros no Porto, tesis de doctorado. Campinas: IFCH/UNICAMP.

Light, I. (1979). «Disadvantaged minorities in self-employment», International Journal of Comparative Sociology, 20: 31-45.

Portes, A. et alii (coord.) (2003). La globalización desde abajo: transnacionalismo inmigrante y desarrollo. México. D.F.: FLACSO. 
Sassen, S. (1997). «Ethnicity in the global city: a new frontier», en Delgado, M. (comp.). Ciutat $i$ immigració. Barcelona: Centre de Cultura Contemporània de Barcelona.

Solé, C.; Parella, S.; Cavalcanti, L. (2007). El empresariado inmigrante en España. Barcelona: La Caixa.

Solé, M.; Rodríguez, J. (2004). «Pakistaníes en España: un estudio basado en el colectivo de la ciudad de Barcelona», Revista CIDOB d'Afers Internacionals, 68: 97 118 .

Vertovec, S. (2001). "Transnationalism and identity», Journal of Ethnic and Migration Studies, 27(4): 573-582.

Vertovec, S. (2004). «Trends and Impacts of Migrant Transnationalism», Policy and Society Working Paper, 3, Centre on Migration, University of Oxford.

Waldinger, R.; McEvoy, D; Aldrich, H. (1990). "Spatial Dimensions of Opportunity Structures», en WALdinger, R. et alii (eds.). Ethnic Entrepreneurs. Immigrant Business in Industrial Societies. Londres: Sage. 